\title{
VACCINES
}

\section{CpG ODN Nanorings Induce IFNa from Plasmacytoid Dendritic Cells and Demonstrate Potent Vaccine Adjuvant Activity}

\author{
Bilgi Gungor, ${ }^{1 *}$ Fuat Cem Yagci, ${ }^{2 *}$ Gizem Tincer, $^{2}$ Banu Bayyurt, ${ }^{2}$ Esin Alpdundar, ${ }^{1}$ Soner Yildiz, \\ Mine Ozcan, ${ }^{1}$ Ihsan Gursel, ${ }^{2}$ Mayda Gursel ${ }^{1+}$
}

\begin{abstract}
CpG oligodeoxynucleotides (ODN) are short single-stranded synthetic DNA molecules that activate the immune system and have been found to be effective for preventing and treating infectious diseases, allergies, and cancers. Structurally distinct classes of synthetic ODN expressing CpG motifs differentially activate human immune cells. K-type ODN (K-ODN), which have progressed into human clinical trials as vaccine adjuvants and immunotherapeutic agents, are strong activators of $B$ cells and trigger plasmacytoid dendritic cells $(p D C s)$ to differentiate and produce tumor necrosis factor- $\alpha$ (TNF $\alpha$ ). In contrast, D-type ODN (D-ODN) stimulate large amounts of interferon- $\alpha$ (IFN $\alpha$ ) secretion from pDCs. This activity depends on the ability of D-ODN to adopt nanometer-sized $\mathrm{G}$ quadruplex-based structures, complicating their manufacturing and hampering their progress into the clinic. In search of a D-ODN substitute, we attempted to multimerize K-ODN into stable nanostructures using cationic peptides. We show that short ODN with a rigid secondary structure form nuclease-resistant nanorings after condensation with the HIV-derived peptide $\operatorname{Tat}_{(47-57)}$. The nanorings enhanced cellular internalization, targeted the ODN to early endosomes, and induced a robust IFNa response from human pDCs. Compared to the conventional K-ODN, nanorings boosted T helper 1-mediated immune responses in mice immunized with the inactivated foot and mouth disease virus vaccine and generated superior antitumor immunity when used as a therapeutic tumor vaccine adjuvant in C57BL/6 mice bearing ovalbumin-expressing EG.7 thymoma tumors. These results suggest that the nanorings can act as D-ODN surrogates and may find a niche for further clinical applications.
\end{abstract}

\section{INTRODUCTION}

Short single-stranded synthetic oligodeoxynucleotides containing cytosine-phosphate-guanine motifs (CpG ODN) stimulate the cells of the innate immune system expressing the pathogen recognition receptor Toll-like receptor 9 (TLR9), generating a robust proinflammatory immune response (1-4). The extensive interest in the immunotherapeutic potential of immunostimulatory ODN led to the development of four structurally different classes of CpG ODN (5). K-class ODN (K-ODN; also known as CpG-B) expressing multiple CpG motifs embedded in a phosphorothioate backbone activate $\mathrm{B}$ cells and stimulate plasmacytoid dendritic cells (pDCs) to secrete tumor necrosis factor- $\alpha$ (TNF $\alpha)(6,7)$. In contrast, D-class ODN (D-ODN; CpG-A) contain a phosphodiester central palindromic $\mathrm{CpG}$ motif capped at each end by a phosphorothioate poly $(\mathrm{G})$ tail $(7,8)$. The combination of the central palindrome and flanking poly $(\mathrm{G})$ enables $\mathrm{D}-\mathrm{ODN}$ to adopt complex nanometer-sized multimeric structures stabilized by Hoogsteen base pairs and confers them their property to stimulate high levels of interferon- $\alpha$ (IFN $\alpha$ ) from pDCs (8-10). The D-ODN-induced robust IFN $\alpha$ response may have potential benefits in the prevention/treatment of viral infections or malignancies. Unfortunately, the formation of such higherorder multimeric structures complicates the manufacturing process of D-ODN, precluding them from human clinical trials (11). Two addi-

\footnotetext{
'Department of Biological Sciences, Middle East Technical University, 06800 Ankara, Turkey. ${ }^{2}$ Department of Molecular Biology and Genetics, Bilkent University, 06800 Ankara, Turkey.

*These authors contributed equally to this work.

tCorresponding author. E-mail: mgursel@metu.edu.tr
}

tional IFN $\alpha$-inducing $\mathrm{CpG}$ ODN classes have also been developed (designated as $\mathrm{C}$ and $\mathrm{P}$ classes) (12-14). However, type I IFN-inducing potency of C-class ODN is substantially low, and the P-class ODN depends on "high-salt buffers" to form IFN $\alpha$-stimulating concatemeric structures, making them unpredictable for clinical applications.

A simple strategy to convert a conventional K-ODN into a type I IFN inducer is to multimerize the ODN using polycationic peptides (15-17). However, polycation-induced condensation of short therapeutic ODN generates aggregates but not ordered nanostructures. To date, efforts to improve ODN condensation largely focused on development of new condensing agents such as poly(amido amine) dendrimers (18), whereas the impact of ODN secondary structure on condensation efficiency remained largely ignored. On the basis of recent reports showing the possibility of spontaneous end-to-end aggregation of short palindromic DNA fragments into rod-like structures (19), we hypothesized that cationic peptide-mediated condensation of a flexible 20-mer CpG ODN and a partially self-complementary rigid 12-mer CpG ODN (fig. S1) would generate disparate nanostructures that can influence the immunostimulatory activity of the final product.

Here, we report that in contrast to the typical ODN/cationic peptide aggregates formed with the human antimicrobial peptide LL-37, HIV-derived cationic peptide $\mathrm{Tat}_{(47-57)}$ formed stable, nuclease-resistant nanorings when mixed with a short K-ODN (12-mer). The nanorings activated $\mathrm{pDCs}$ to secrete IFN $\alpha$ and proved to be potent vaccine adjuvants in mice. These results demonstrate that $\mathrm{K} /$ Tat nanorings can replicate D-ODN activity and could find application in the clinic as vaccine adjuvants and anticancer and antiviral agents. 


\section{RESULTS}

\section{Cationic peptide Tat $_{(47-57)}$-induced condensation of a 12-mer K-ODN generates ordered nanostructures}

To assess whether complexation of K-ODN with cationic peptides of various length, amphiphilicity, and charge densities would generate welldefined, stable nanoparticles suitable for clinical applications, a fixed amount of a 12-mer K-ODN was mixed with increasing molar ratios of three different cationic peptides: HIV-Tat-derived peptide (YGRKKRRQRRR; net charge of +8 ) (20), human cathelicidin family antimicrobial peptide LL-37 (LLGDFFRKSKEKIGKEFKRIVQRIKDFLRNLVPRTES; net charge of +6$)(21,22)$, and the shortest biologically active derivative of LL-37, KR-12 (KRIVQRIKDFLR; net charge of +4) (22). These three cationic peptides were chosen as representatives of a long amphiphilic peptide previously shown to have a role in sensing of extracellular nucleic acids (LL-37; 37-mer; 54\% hydrophilic) (15-17), a short amphiphilic peptide derived from LL-37 (KR-12; 12-mer; 58\% hydrophilic), and a short hydrophilic peptide with well-characterized cell penetration properties [Tat ${ }_{(47-57)} ; 11$-mer; $82 \%$ hydrophilic]. Complexes were then characterized in terms of their particle size, $\zeta$ potential, and polydispersity index (PI) (Fig. 1A). $\zeta$ Potential is a physical property exhibited by particles in suspension and is an important indicator of stability of the particles in colloidal systems. It shows the amount of repulsion between similarly charged molecules. Therefore, if the $\zeta$ potential is very low, attractive forces surpass repulsive forces and particles will come together to form aggregates. Particles with large negative or positive $\zeta$ potentials that are small in size resist attraction and are hence electrically stabilized. In general, particles with $\zeta$ potentials larger than $+30 \mathrm{mV}$ or smaller than $-30 \mathrm{mV}$ are considered as stable. Stability is also designated by the PI. In cases where $\mathrm{PI}$ value is greater than 0.5 , sample is too polydisperse, indicating the presence of very large or aggregated particles. On the basis of the above information, dynamic light scattering revealed that the hydrodynamic sizes of Tat-incorporating complexes were significantly smaller ( $\sim 300 \mathrm{~nm} ; P=0.0028$ as determined by the Kruskal-Wallis test for the three highest ODN/peptide ratios; $n=6$ ) than those incorporating either LL-37 or KR-12 and were independent of ODN/peptide ratio. $\zeta$ Potential measurements indicated that among the complexes tested, only three [K/LL-37 (1:8), K/Tat $(1: 8)$, and $\mathrm{K} / \mathrm{Tat}(1: 16)]$ demonstrated sufficiently high values $(>+30 \mathrm{mV})$ that could be considered as stable nanoparticles. On the basis of a PI of $<0.15, \mathrm{~K} / \mathrm{Tat}$ (1:16) was the sole complexation condition that formed uniform and monodispersed particles. Note that in contrast to Tat or KR-12, LL-37 has a high molecular weight, precluding its testing at an ODN/peptide ratio
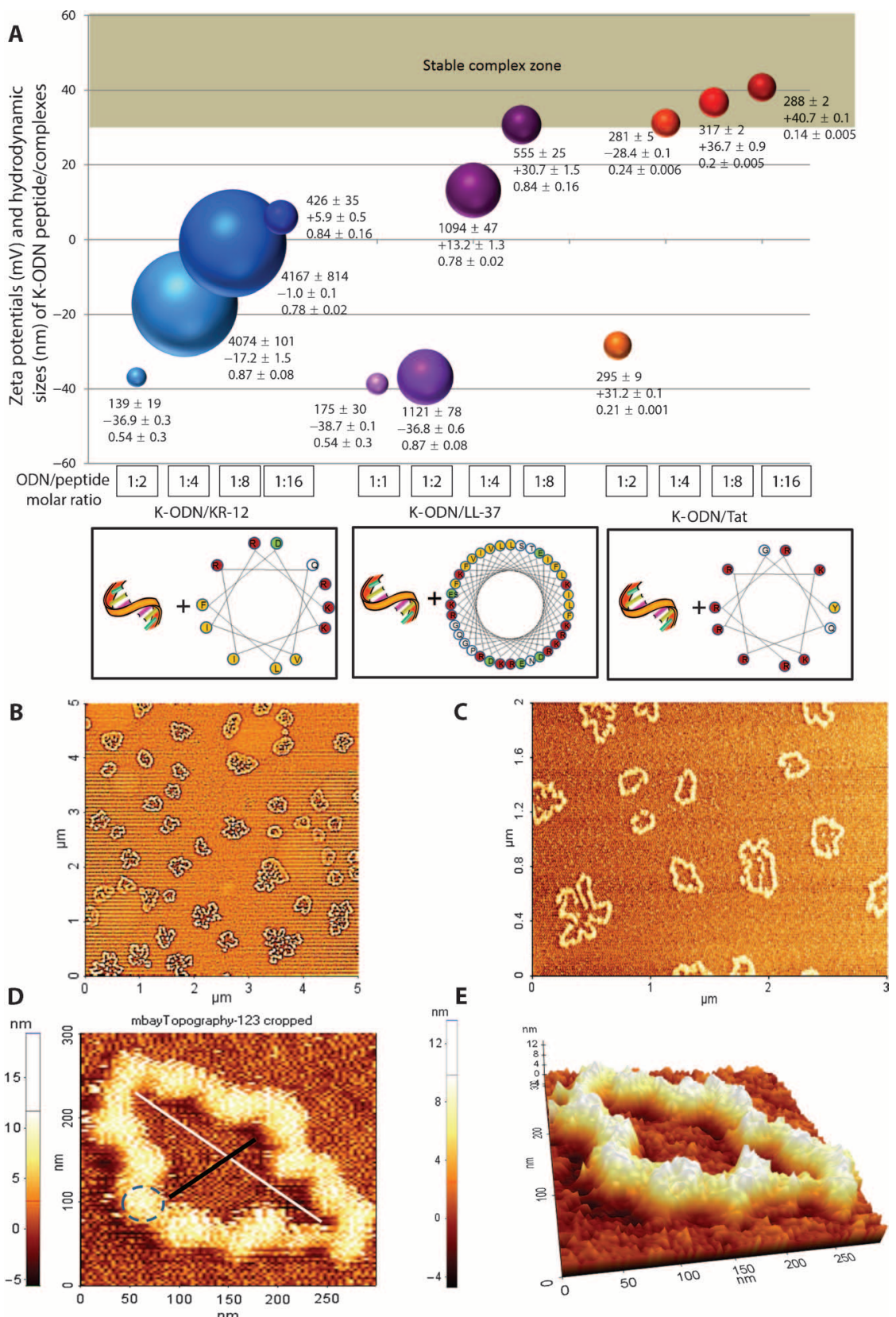

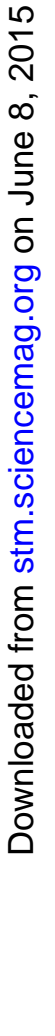

Fig. 1. Physical properties of CpG ODN/cationic peptide complexes prepared using various ODN/peptide ratios. (A) Average particle size (size of each bubble correlates with the hydrodynamic diameter) and $\zeta$ potential (vertical axis) of each complex. Numbers next to each bubble represent the mean hydrodynamic size ( $\mathrm{nm}$; top), $\zeta$ potential ( $\mathrm{mV}$; middle), and $\mathrm{PI}$ (bottom) of two to four separately prepared samples, each measured in triplicate \pm SD. Particles incorporating KR-12, LL-37, and Tat are shown as blue, purple, and red bubbles, respectively. Increasing ODN/peptide ratio is indicated as an increase in color depth. Particles with a $\zeta$ potential of $>+30 \mathrm{mV}$ are considered to have sufficient stability, and this "stable complex zone" is indicated by a gray rectangle. (B and $\mathbf{C}$ ) AFM images showing nanorings formed using $\mathrm{K} / \mathrm{Tat}$ (1:16). (D) AFM image of a single nanoring showing the diameter of one condensed building block (dashed blue circle; about $40 \mathrm{~nm}$ ) and the 250-nm-long (white bar), 100-nm-wide (black bar) central hollow area. (E) Three-dimensional topography image of the nanoring demonstrates its flat nature (thickness of about $8 \mathrm{~nm}$ ). The AFM results are representative of at least two independent samples. 
of 1:16, because this required preparation of a concentrated LL-37 solution beyond its solubility limit ( 2 to $5 \mathrm{mg} / \mathrm{ml})$. Of interest, all LL-37incorporating complexes generated size intensity histograms composed of two peaks as opposed to a single, well-defined size peak with less heterogeneity when Tat was used (fig. S2A). On the basis of size and $\zeta$ potential measurements, KR-12 peptide-incorporating complexes were considered as highly unstable and were not pursued in later studies.

Replacing the 12 -mer K-ODN with a 20 -mer one resulted in complexes with significantly lower $\zeta$ potentials $(P=0.036$ for the highest ODN/peptide ratios as determined by Student's $t$ test; table S1), suggesting that the more flexible longer ODN fails to form stable monodisperse nanoparticles with Tat.

Atomic force microscopy (AFM) analysis of LL-37-incorporating particles showed aggregates of various sizes and ill-defined shapes (fig. S2B). Such heterogeneity in particle size and shape would make these aggregates unsuitable for clinical applications. In contrast, the 12-mer K/Tat peptide combination (1:16) generated 200- to 300-nm-sized nanorings (Fig. 1, B and C), each made up of smaller condensed building blocks with diameters of about $40 \mathrm{~nm}$ (Fig. 1D). The central hollow area of one such ring was $\sim 250 \times 100 \mathrm{~nm}(L \times W)$. The nanorings were flat and had a thickness of $\sim 8 \mathrm{~nm}$ (Fig. 1E). K/Tat peptide (1:8) formed a combination of nanorings and individual spherical condensates (fig. S2C), whereas when a 1:4 ratio was used, only separate spherical condensates were present (fig. S2D). Such multivalent cation-induced plasmid DNA condensation into nanorings (or toroids) was previously reported $(23,24)$. However, short ODN are quite rigid and are not as easily condensed into ordered structures (25). It is conceivable that the 11-mer Tat peptide first condenses the 12-mer ODN to form rigid individual building blocks that interact with each other to neutralize the local polar charges and subsequently form rings to reduce the surface charge density, a process reminiscent of nanorings formed from nanobelts (26). The 20-mer flexible ODN with a long overhang would fail to pack as the rigid 12-mer ODN and would condense into spherical aggregates but not nanorings.

\section{$\mathrm{K} / \mathrm{Tat}$ nanorings are potent inducers of IFNa secretion from human pDCs and are nuclease-resistant}

To ascertain whether the K/Tat nanorings could reproduce the immunostimulatory activity of D-ODN, human peripheral blood mononuclear

A

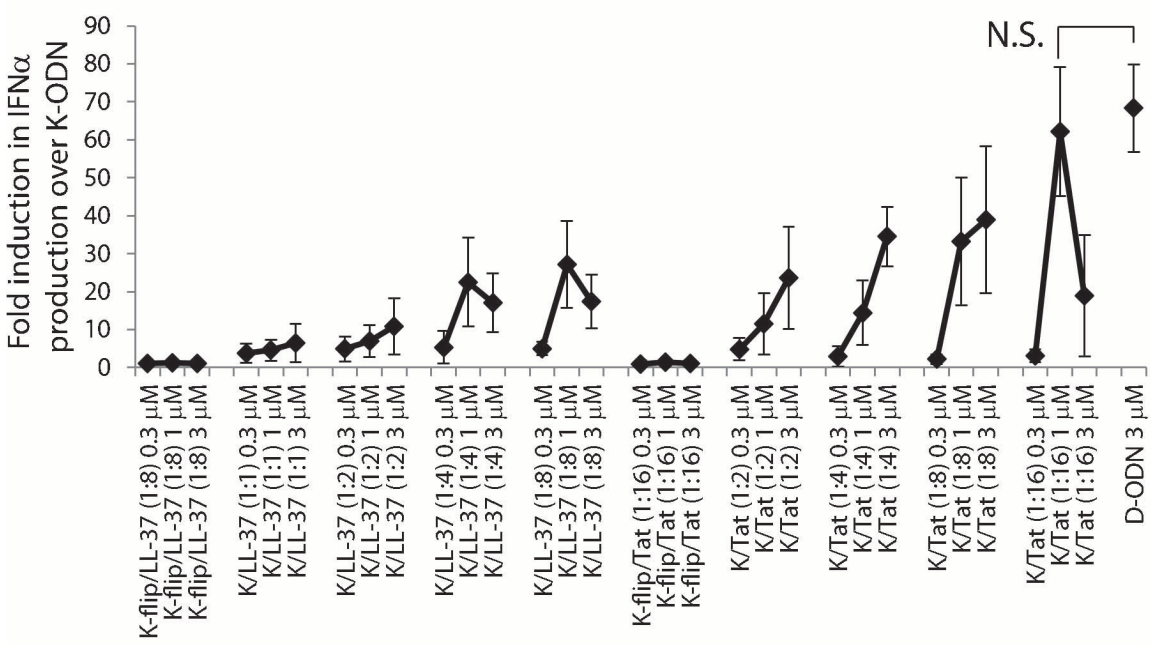

C

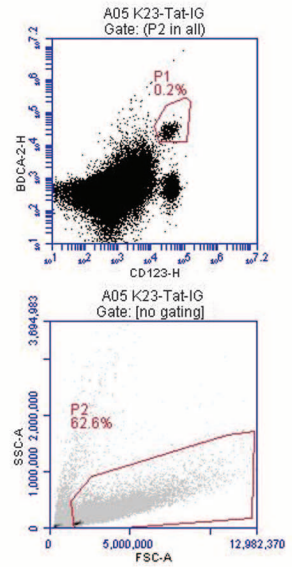

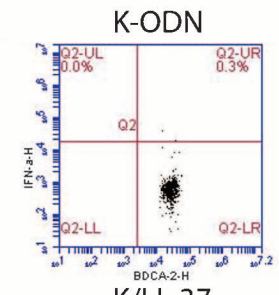

K/LL-37

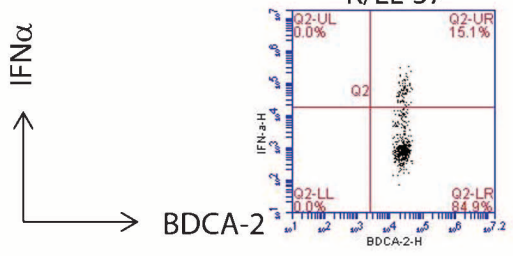

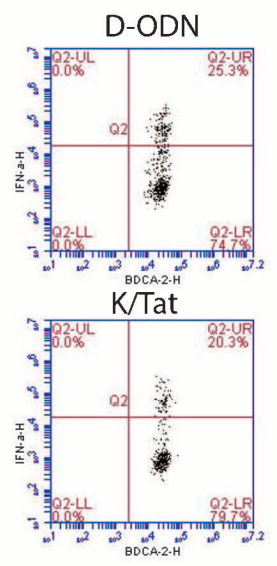

B

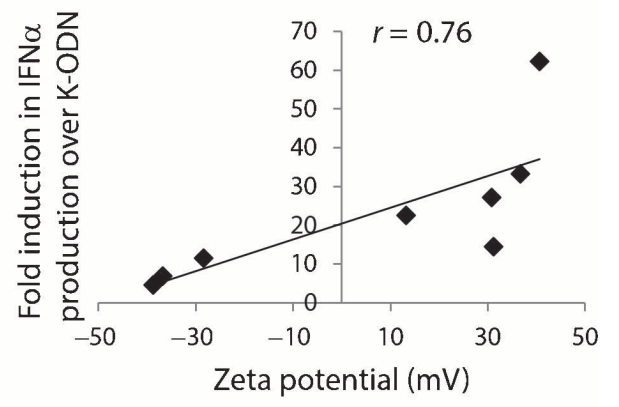

Fig. 2. IFNo-stimulating activity of various CpG ODN/cationic peptide complexes in hPBMCs in comparison to D-ODN activity. (A) Complexation of K-ODN but not its CpG flipped control (K-flip) with LL-37 and Tat induces IFN $\alpha$ production from hPBMCs (shown as fold induction over K-ODNinduced IFN $\alpha$ levels). Only the $\mathrm{K} / \mathrm{Tat}(1: 16,1 \mu \mathrm{M})$ nanorings induced high levels of IFN $\alpha$ that was not statistically different from D-ODN-stimulated samples ( $3 \mu \mathrm{M}$ optimum dose). Results are the average \pm SD of five to eight different PBMC samples. For groupwise comparisons, stimulation indexes (fold induction) were subjected to the Mann-Whitney $U$ test $(n=5)$. N.S., not significant. (B) IFN $\alpha$-inducing activity correlates with particle stability (the plot was generated using $1 \mu \mathrm{M}$ dose for all complexes; $r$ is the correlation coefficient). (C) D-ODN (3 $\mu \mathrm{M}$

optimum D-ODN dose), K/LL-37 aggregates $(1: 8,1 \mu \mathrm{M})$, and $\mathrm{K} /$ Tat nanorings (1:16, $1 \mu \mathrm{M})$ triggered IFNo production from pDCs, whereas $\mathrm{K}-\mathrm{ODN}(1 \mu \mathrm{M})$ and unstimulated controls did not. pDCs were defined using a live cell gate (P2) and blood dendritic cell antigen-2 (BDCA-2; also known as CD303)/CD123 double positivity (P1). The ungated BDCA-2 $/ \mathrm{CD} 123^{+}$cells are basophils. Results are representative of four independent samples. 
cells (hPBMCs) were stimulated with K-ODN/peptide complexes of various molar ratios and concentrations, and the potency of cytokine production was compared to that induced by the optimum dose of free D-ODN $(3 \mu \mathrm{M})(9,27)$. Among the 10 different complexes (each tested using three different doses), only the nanoring forming formulation triggered IFN $\alpha$ release to levels that were not statistically different from the D-ODN-induced IFN $\alpha$ [K/Tat (1:16), $1 \mu \mathrm{M}$; Fig. 2A and table S2]. LL-37-incorporating aggregates triggered a substantially lower response. IFN $\alpha$ production was strictly dependent on the presence of the $\mathrm{CpG}$ dinucleotide motif because complexes prepared with a 12-mer GpC flipped control ODN (K-flip) had no activity (Fig. 2A). IFNo-inducing activity correlated strongly with the $\zeta$ potential of complexes (Fig. $2 \mathrm{~B}$, $r=0.76$ ), whereas no such correlation was found with respect to particle size (fig. S3, $r=-0.198$ ). Similar to D-ODN-stimulated PBMCs, ODN/peptide complexes stimulated IFN $\alpha$ production specifically from pDCs (Fig. 2C).

The effect of ODN backbone chemistry and ODN length was also determined in experiments where the complexes were prepared with the maximum ODN/peptide ratio (1:8 for LL-37 and 1:16 for Tat) using either a phosphodiester (PO) 12-mer K-ODN or a 20-mer phosphorothioate (PS) ODN. Results show that ODN backbone and length had a critical impact on IFN $\alpha$-inducing activity of the complexes (fig. S4). For optimal induction, the use of the 12-mer PS backbone K-ODN was essential. These results suggest that $\mathrm{K} /$ Tat nanorings can be effective $\mathrm{D}-\mathrm{ODN}$ mimetics. Of interest, aggregates and nanorings were not cytotoxic (fig. S5A) and did not trigger inflammasome activation in lipopolysaccharide-primed thioglycolate-elicited mouse peritoneal macrophages (fig. S5B).
Direct D-ODN activation of pDCs was previously shown to trigger secretion of IFN $\alpha$ and other soluble factors that synergize to induce monocytes to secrete high levels of the T helper $1\left(\mathrm{~T}_{\mathrm{H}} 1\right)$-promoting chemokine IFN $\gamma$-inducible protein-10 (IP-10) (28). When secretion of this chemokine was tested, all Tat-incorporating complexes and only the K/LL-37 (1:8) complex was found to induce substantial IP-10 production that was not statistically different when compared to D-ODN-stimulated samples (Fig. 3A and table S3). As expected, the presence of the CpG motif was required for this activity, and aggregates or nanorings incorporating the control ODN K-flip were not active. Similar to D-ODN, K/Tat (1:16) nanorings increased the percentage of IP-10-producing monocytes about sevenfold over K-ODN-stimulated samples (Fig. 3B). In contrast to $\mathrm{D}-\mathrm{ODN}(9,27)$, an interesting feature of the nanorings and the aggregates was their ability to stimulate TNF $\alpha$ release from pDCs (fig. S6) to similar levels observed with K-ODN-induced samples. Thus, the K-ODN present in these complexes retained its TNFo-inducing ability, which may further contribute to the activation of natural killer cells and cytotoxic T cells.

One important factor that affects the in vivo therapeutic activity of CpG ODN is their susceptibility to degradation by nucleases. Although PS-modified ODN display increased nuclease resistance, they are still prone to degradation. To assess whether the ODN in nanorings would be protected from this assault, we compared IP-10-inducing activity of untreated versus deoxyribonuclease (DNase)-treated complexes (Fig. 3C and table S4). Nanorings retained 70 to $80 \%$ of their IP-10 stimulatory activity after a 30 -min exposure to DNase. In contrast, LL-37/ODN (1:8) aggregates retained only $40 \%$ of their activity, suggesting a lower efficiency of condensation/protection.
A
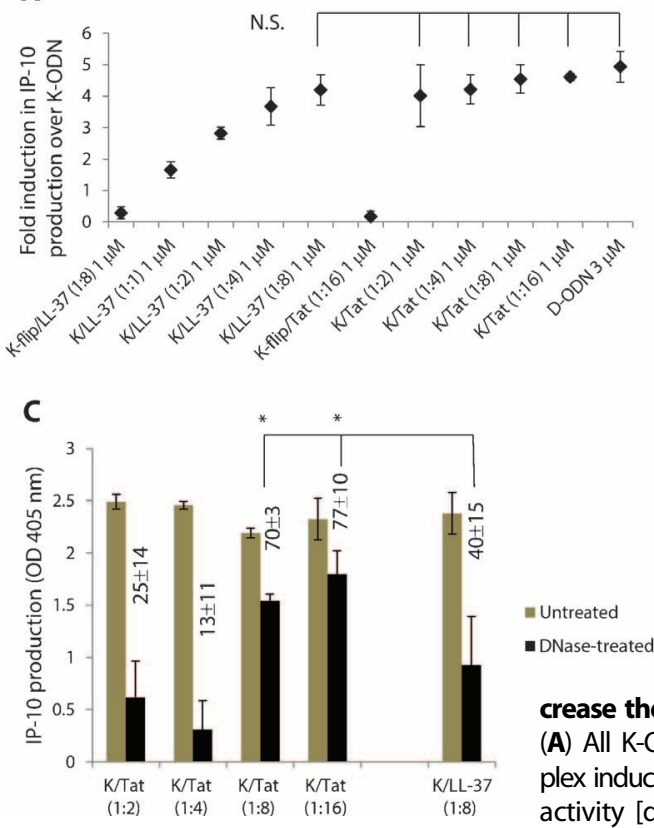
the average \pm SD of five different PBMC samples. For groupwise comparisons, stimulation indexes (fold induction) were subjected to the Mann-Whitney $U$ test $(n=5)$. (B) D-ODN (3 $\mu$ M optimum D-ODN dose), K-ODN $(1 \mu \mathrm{M})$, and $\mathrm{K} /$ Tat nanorings $(1: 16,1 \mu \mathrm{M})$ triggered IP-10 production from CD14 ${ }^{+}$monocytes. Results are representative of three independent samples. (C) K/Tat nanorings (1:8 and 1:16) protect their CpG content from nuclease digestion significantly better than K/LL-37 aggregates. Sample means were compared to the mean of K/LL-37 stimulated group using the Student's $t$ test $(n=3)$. ${ }^{*} P<0.05[P=0.046$ for $\mathrm{K} / \mathrm{Tat}(1: 8)$ and $P=0.013$ for $\mathrm{K} / \mathrm{Tat}(1: 16)]$.
B
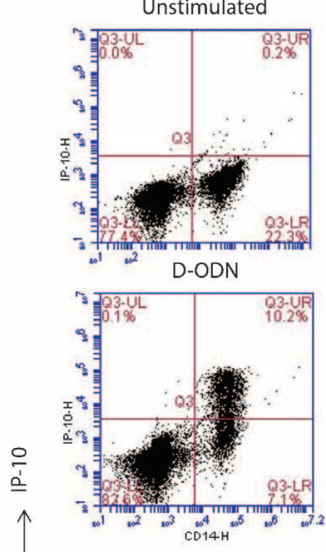

Fig. 3. K/LL-37 aggregates and $\mathrm{K} /$ Tat nanorings induce IP-10 secretion from monocytes and increase the nuclease resistance of the associated CpG ODN. (A) All K-ODN/Tat complexes and only the K/LL-37 (1:8) complex induced IP-10 production comparable to D-ODN-stimulated activity [determined by enzyme-linked immunosorbent assay (ELISA) from 24-hour culture supernatants]. Results are

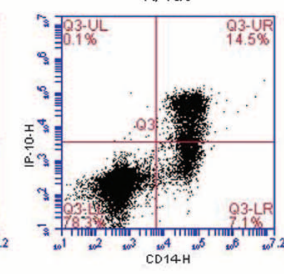

Tat peptide-induced condensation enhances cellular internalization and early endosomal localization of the K-ODN

Next, using the human pDC-like CAL-1 cells (29), we studied the cellular internalization properties and subcellular distribution of the LL-37/ODN aggregates (1:8) and $\mathrm{K} /$ Tat (1:16) nanorings, because these conditions proved to be the most stable and potent formulations for their respective peptides. For this, complexes were prepared with fluorescein amidite (FAM)-labeled $\mathrm{K}-\mathrm{ODN}$, and cell-associated fluorescence was measured before and after trypan blue quenching to enable discrimination between surface-bound + internalized and internalized signal only. All samples displayed a dose-dependent increase in the percentage of cells positive for surfacebound + internalized and internalized ODN signal before and after trypan blue quenching, respectively (Fig. 4A). About 35\% of cells were positive for internalized K-ODN at the highest dose. Complexation led to a significant increase in this number $(P<$ $0.05,80 \%$ for K/LL-37 aggregates and 95\% for K/Tat nanorings). Analysis of mean fluorescence intensities (MFIs), reflecting the quantity of cell-associated ODN, revealed 

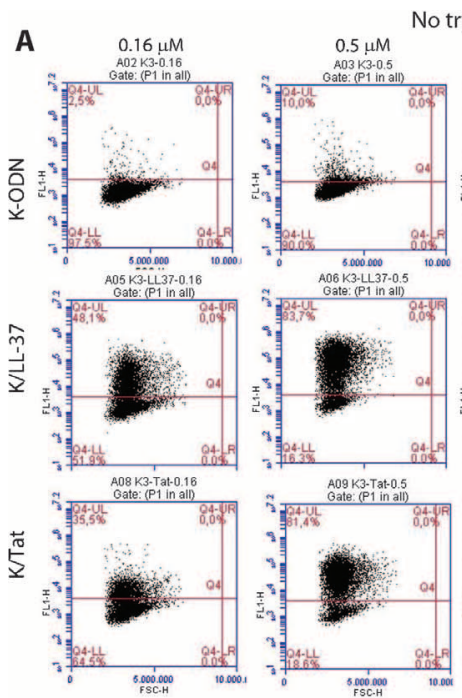

No trypan blue
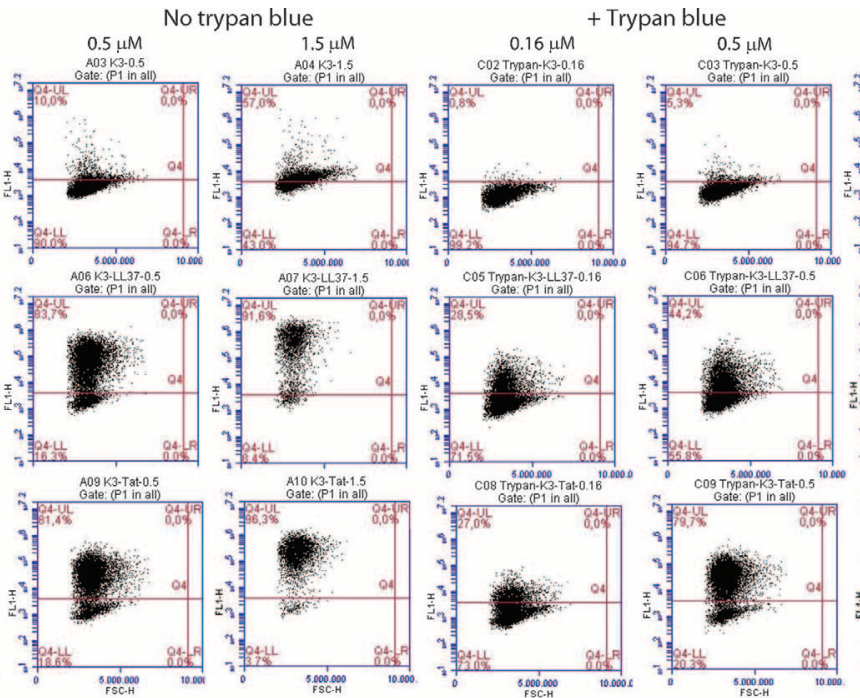

B
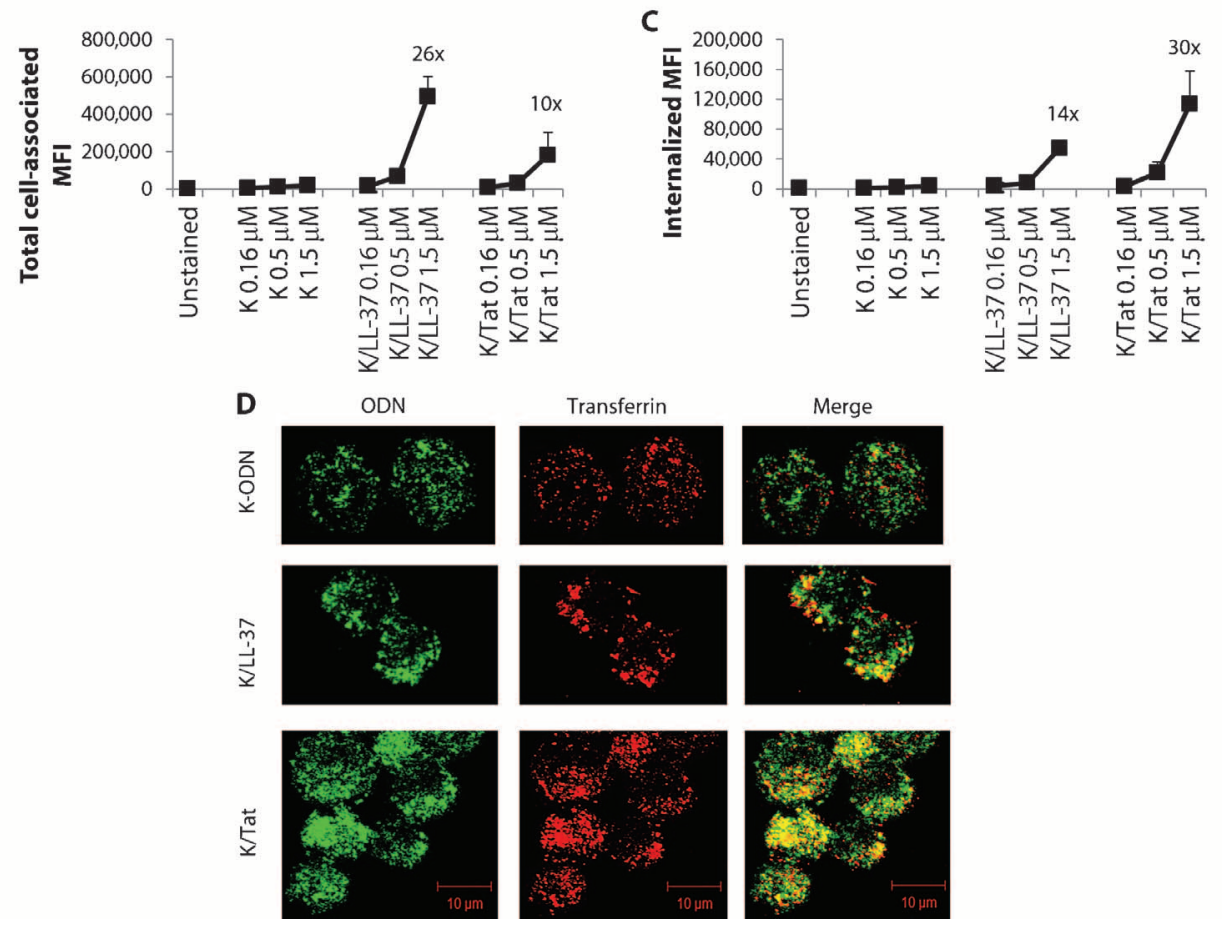

Fig. 4. Cellular internalization properties and subcellular localization of K/LL-37 aggregates and K/Tat nanorings. (A) Percent of CAL-1 plasmacytoid-like DCs positive for cell surface-bound and internalized FAMlabeled ODN (No trypan blue) or internalized ODN alone (+ Trypan blue) after 1-hour incubation with three different doses $(0.16,0.5$, and $1.5 \mu \mathrm{M})$ of K-ODN, K/LL-37 aggregates, or K/Tat nanorings. Dot plots show FAMassociated ODN fluorescence (FL1) versus forward scatter (FSC). (B) Quantification of total cell-associated fluorescence (based on MFIs), revealing that MFI increased 26-fold with K/LL-37 and 10-fold with K/Tat over K-ODN alone at the highest ODN dose. (C) Quantification of internalized fluorescence (based on MFls obtained after trypan blue quenching) showing that compared to K-ODN alone, K/LL-37 aggregates and K/Tat nanorings improved internalized ODN amount 14- and 30-fold, respectively. (D) Confocal microscopy of CAL-1 cells treated with free or peptide-associated ODN (green) for 1 hour shows that K/LL-37 aggregates and K/Tat nanorings, but not K-ODN, localize to transferrin-positive (red) vesicles.

that surface-bound + internalized signal increased 26-fold with K/LL-37 and 10-fold with K/Tat (Fig. 4B) over K-ODN alone. However, internalizedonly signal increased only 14 -fold with the K/LL-37 aggregates as op-
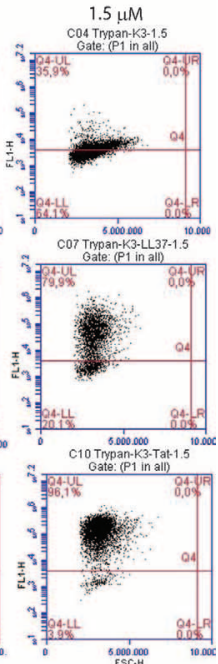

posed to a 30-fold enhancement when $\mathrm{K} /$ Tat nanorings were used (Fig. 4C). This suggests that $\sim 50 \%$ of LL-37incorporating aggregates remain plasma membrane-associated, whereas almost all of the K/Tat nanorings were efficiently internalized.

Previous studies have shown that the differential immune activation induced by K-ODN versus D-ODN correlates with their subcellular distribution profiles in pDCs: K-ODN localize to late endosomes and trigger TNF $\alpha$ production through the TLR9-MyD88-IRF5 pathway, whereas D-ODN accumulate in transferrinpositive early endosomes and stimulate IFN $\alpha$ production via a TLR9-MyD88IRF7-dependent pathway $(27,30,31)$. Similar to D-ODN and in contrast to K-ODN, K/LL-37 aggregates and $\mathrm{K} /$ Tat nanorings preferentially localized to transferrin-positive early endosomes (Fig. 4D), consistent with their IFNo-inducing activities.

\section{$\mathrm{K} /$ Tat nanoring adjuvanted vaccines induce potent $T_{H}$ 1-dependent antigen-specific immune responses in mice}

Type I IFNs play important roles in regulating adaptive immune responses through both direct and indirect effects and are considered as the "third signal" that shapes the effector and memory $\mathrm{T}$ cell pool $(32,33)$. They contribute to $\mathrm{T}$ cell-mediated interleukin-2 secretion from $\mathrm{CD}^{+}$central memory cells (34). Moreover, they directly trigger clonal expansion and memory formation in $\mathrm{CD}^{+} \mathrm{T}$ cells (35). These properties make type I IFN inducers attractive vaccine adjuvants predominantly in cases where the development of immunological memory is taxing. We therefore chose to compare the vaccine adjuvant properties of the ODN/ peptide aggregates and nanorings to K-ODN using a commercially available inactivated viral vaccine developed against one of the most economically devastating livestock diseases, the foot and mouth disease (FMD). This vaccine is explicitly problematic because protective antibodies produced by a single vaccination tend to be short-lived, and subsequent vaccinations do not stimulate the development of immunological memory (36). As a consequence, to provide protection, animals have to be vaccinated 
every 4 to 6 months. Moreover, the disease afflicts developing countries with limited resources, where "vaccine dose sparing" could critically contribute to economic welfare, especially during an epidemic (37). Thus, to test whether we could expand the supplies of the FMD vaccine and improve long-term immunity, mice were primed and boosted (days 0 and $28)$ with a $5 \times$ lower dose of the FMD vaccine $(0.5 \mu \mathrm{g}$; determined in preliminary experiments) in the absence or presence of the adjuvants $(2 \mu \mathrm{g}$ each of K-ODN, K/LL-37 aggregates, or K/Tat nanorings). This dose of CpG ODN is lower than the typical dose used in mouse vaccine studies $(10$ to $50 \mu \mathrm{g})(38)$ and was chosen to enable comparison of vaccine adjuvant potencies. Long-term FMD-specific antibody responses were evaluated from sera of immunized mice collected 180 days after priming. The data are expressed as mean $\log _{2}$ reciprocal immunoglobulin $G(\operatorname{IgG})$ titers \pm SD. One-way analysis of variance (ANOVA) and the Tukey's honestly significant difference (HSD) post hoc test were used to determine which groups were significantly different from the rest. The results showed that mice vaccinated with the FMD vaccine generated similar titers of FMD-specific IgG1 antibody compared to those immunized with the vaccine plus adjuvants (Fig. 5A and table S5). In contrast to the adjuvanted groups, FMD vaccine alone did not trigger detectable FMD-specific IgG2a antibody response (Fig. 5B). Notably, K/Tat nanorings elicited 6- and 33-fold higher titers of FMD-specific IgG2a when compared to K + FMD and K/LL-
A

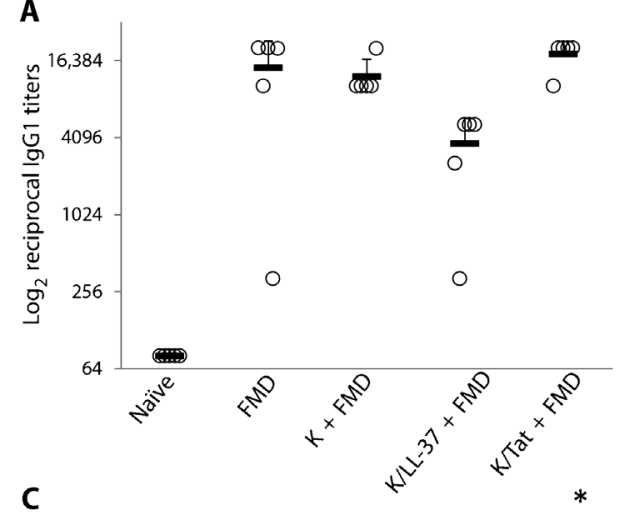

C

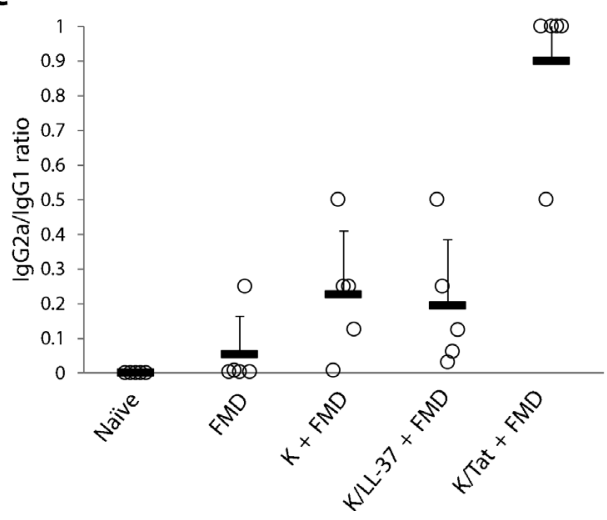

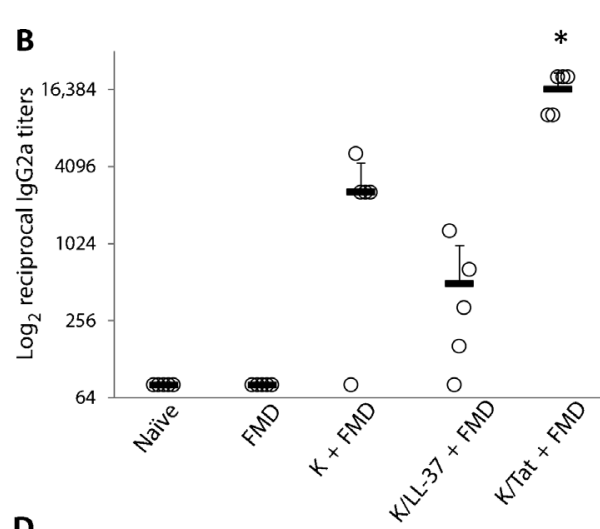

D

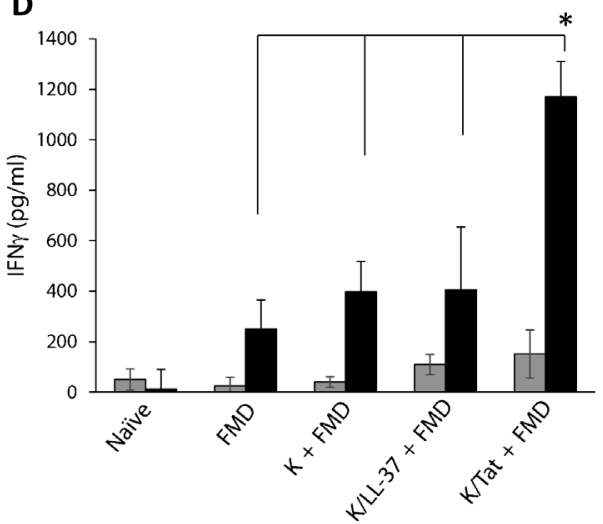

Fig. 5. FMD-specific immune responses generated in mice. (A and $\mathbf{B}$ ) FMD serotype O-specific lgG1 (A) and lgG2a (B) $\log _{2}$ reciprocal titers were determined from sera of mice 6 months after priming. Each circle corresponds to the antibody titer of individual mice, and horizontal lines indicate mean antibody titers \pm SD. (C) $\operatorname{lgG} 2 \mathrm{a} / \mathrm{lgG} 1$ titer ratios of individual mice (open circles) and group averages (horizontal lines). (D) FMD antigen-specific IFN $\gamma$ production was determined from in vitro antigen restimulated splenocytes (black bars) of immunized mice. Gray bars show the response in the absence of antigen. Results are the average \pm SD of five mice. ${ }^{*} P<0.05$ for all groups based on Tukey's HSD post hoc test using one-way ANOVA (HSD values and comparisons are shown in table S5).
$37+$ FMD vaccinated groups, respectively (Fig. 5B, $P<0.05$ based on the HSD values shown in table S5). K/Tat nanorings were the only adjuvant group that induced a substantial and significant increase in antiFMD IgG2a/IgG1 ratio, consistent with a shift toward a predominantly $\mathrm{T}_{\mathrm{H}} 1$-dominated response (Fig. $5 \mathrm{C}$ and table $\mathrm{S} 5$ ). Finally, as a measure of -mediated immunity, in vitro FMD antigen restimulation of splenoadjuvanted with the K/Tat nanorings induced a significant increase in antigen-specific IFN $\gamma$ production (3.8-fold) when compared to the FMD vaccinated group (Fig. 5D and table S5). These results suggest that $\mathrm{K} / \mathrm{Tat}$ nanorings are more effective in stimulating antigen-specific $\mathrm{T}$ cell responses.

Several studies have previously shown that in the EG.7/EL4 murine lymphoma model, CpG ODN treatment resulted in significant suppression of tumor growth (39-43). Therefore, we next compared the antitumor vaccine adjuvant activities of $\mathrm{K}-\mathrm{ODN}$ versus the $\mathrm{K} / \mathrm{T}$ at nanorings y therapeutically vaccinating C57BL/6 mice bearing ovalbumin (OVA)intraperitoneally with $25 \mu \mathrm{g}$ of OVA plus K-ODN or K/Tat nanorings (10 $\mu \mathrm{g}$ of ODN, each) 1 week apart. As seen in Fig. 6A, OVA + K/Tat nanorings significantly decreased the growth of subcutaneous tumors over time when compared to OVA + K-ODN-treated groups (Fig. 6A; $P=$ $0.0005,0.0004,0.0003,0.0024$, and 0.0001 on days $2,4,6,8$, and 10 , respectively). Average tumor weight of the $\mathrm{K} /$ Tat nanoring adjuvanted group was about fourfold lower at sacrifice $(P=0.0001$, Fig. $6 \mathrm{~B})$, and the tumors were much smaller than those formed in the K-ODN-incorporating group (Fig. $6 \mathrm{C})$. In contrast to the K-ODN adjuvanted group, $\mathrm{K} /$ Tat nanorings stimulated significant expansion in the number of $\mathrm{CD}^{+} \mathrm{T}$ cells (from $5.5 \pm 0.4$ to $10.1 \pm 0.2, P=$ 0.0001 , Fig. 6D) and induced 2.4-fold more antigen-specific IFN $\gamma$ from this population $(P=0.0017$, Fig. $6 \mathrm{E})$. These results suggest that $\mathrm{K} /$ Tat nanorings are more effective than the K-ODN in stimulating tumor-specific cytotoxic $\mathrm{T}$ cell responses.

\section{$\mathrm{K} /$ Tat nanoring vaccine adjuvant activity is dependent on the presence of pDCs}

To assess whether K/Tat nanoring activity requires the presence of $\mathrm{pDCs}$, we next depleted this cell population in vivo to examine the role of these cells in the induction of antibody responses to the model antigen OVA. For this, mice were treated intraperitoneally with phosphatebuffered saline (PBS) (undepleted groups) or an antibody to mouse plasmacytoid dendritic cell antigen 1 (mPDCA-1), and then immunized 24 hours later with $\mathrm{K} / \mathrm{Tat}+$ OVA or D-ODN + OVA. Depletion of pDCs was confirmed in the peripheral blood on the day of immunization (Fig. 7A). OVAspecific IgG1 and IgG2a antibody responses 
A

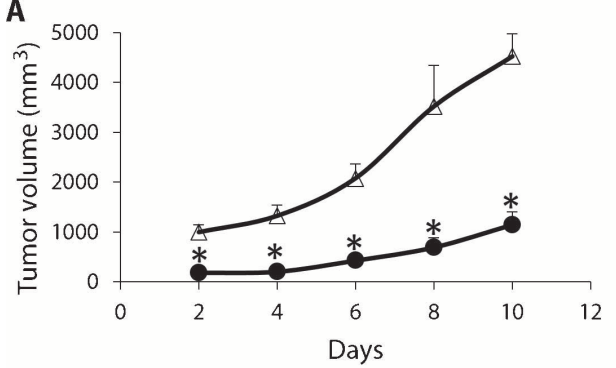

B

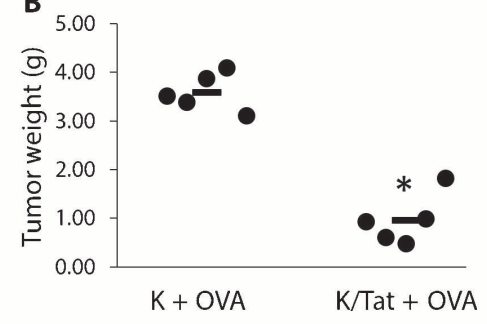

$\mathrm{K}+$ OVA

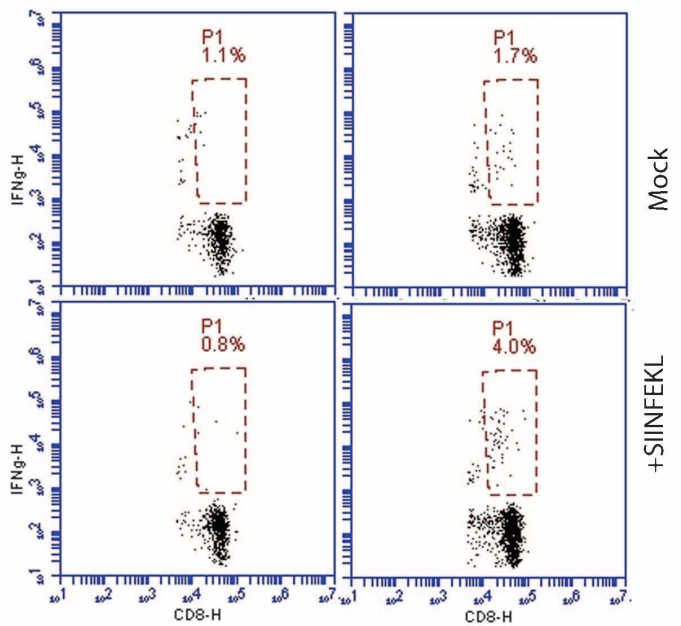

$\mathbf{E}$

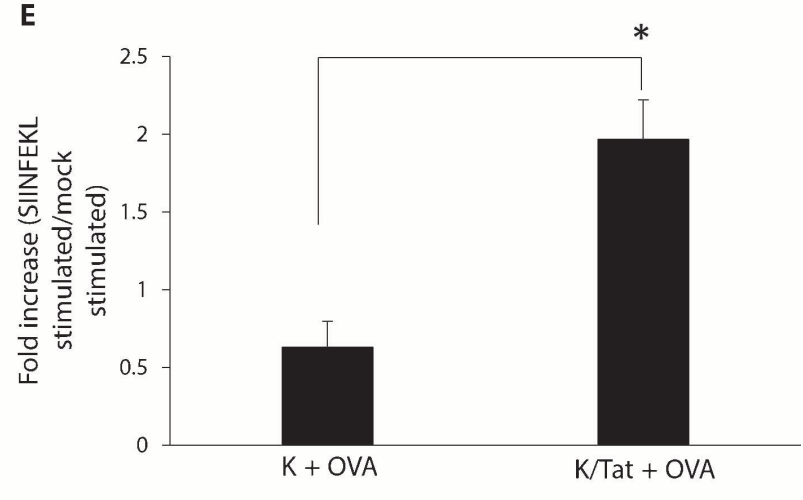

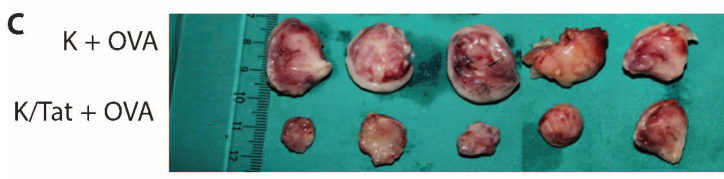

D
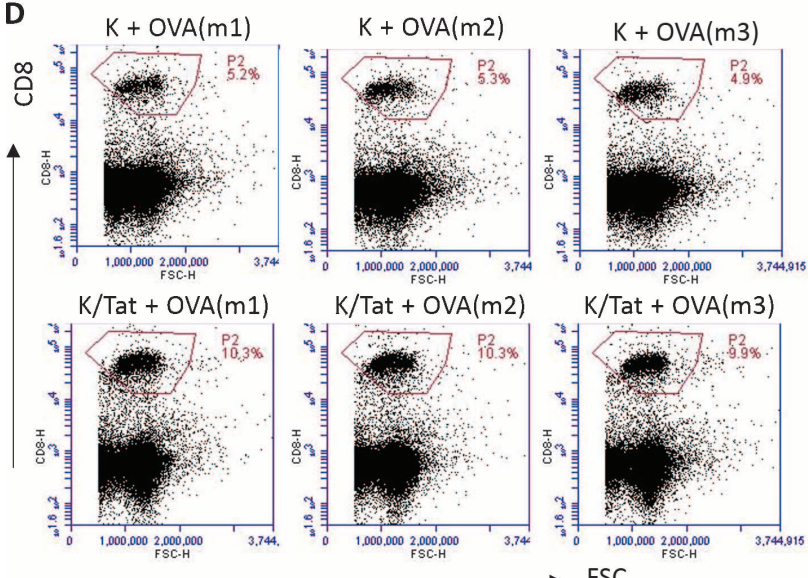

Fig. 6. Antitumor vaccine adjuvant activities of $K-O D N$ versus the $K / T a t$ nanorings. (A) EG.7 cells $\left(2.5 \times 10^{6}\right)$ were subcutaneously inoculated into C57BL/6 mice. When the tumor mass became palpable ( $\geq 50 \mathrm{~mm}^{3}$, typically 5 days later), the tumor-bearing mice were injected intraperitoneally with $25 \mu \mathrm{g}$ of OVA $+10 \mu \mathrm{g}$ of K-ODN (open triangles) or $25 \mu \mathrm{g}$ of OVA $+10 \mu \mathrm{g}$ of $\mathrm{K} /$ Tat nanorings (closed circles). Data represent the progression in mean tumor volumes \pm SD of five mice per group. (B and $\mathbf{C}$ ) Twelve days after tumor cell

were evaluated from sera of immunized mice collected 14 days after immunization (Fig. 7, B and C). OVA-specific IgG1 titers were similar in all OVA-immunized groups regardless of their $\mathrm{pDC}$ depletion status or adjuvant identity (Fig. 7B). In sharp contrast, K/Tat and D-ODN adjuvanted groups generated 75- and 85-fold higher OVA-specific IgG2a titers when compared to antigen alone, and this activity was severely impaired in pDC-depleted mice (Fig. 7C, $P=0.0404$ for K/Tat and D-ODNundepleted versus pDC-depleted groups; Mann-Whitney $U$ test; $n=3$ ). These results suggest that $\mathrm{K} / \mathrm{Tat}-$ and $\mathrm{D}-\mathrm{ODN}$-induced $\mathrm{pDC}$ activation is essential for the generation of $\mathrm{T}_{\mathrm{H}} 1$-dominated responses to OVA vaccination.

\section{DISCUSSION}

Type I IFNs play important roles in regulating innate and adaptive immune responses by participating in maturation and trafficking of DCs, establishment of effector and memory $\mathrm{T}$ cell responses, and stim- injection, excised tumors were weighed (B) and photographed (C). Splenocytes $\left(2.5 \times 10^{6} / \mathrm{ml}\right)$ were stimulated in the absence or presence of SIINFEKL peptide $(2 \mu \mathrm{g} / \mathrm{ml})$ for 5 hours together with brefeldin A $(10 \mu \mathrm{g} / \mathrm{ml})$. (D and E) Cells were stained for cell surface CD8 expression (D), and after gating on this population, intracellular IFN $\gamma$ production (E) was assessed by flow cytometry. Statistical comparison between groups was based on two-tailed unpaired Student's $t$ test $(n=3$ to 5$)$.

ulation of humoral immunity. Therefore, development of type I IFN inducers as antiviral/anticancer agents and/or vaccine adjuvants may have potential clinical applications. The therapeutic potential of one such type I IFN inducer, D-ODN, remained largely unexplored owing to formation of uncontrollable product aggregation that complicates their manufacture and hampers their approval by the U.S. Food and Drug Administration. The current study aimed to convert a conventional K-ODN suitable for clinical use but devoid of IFN $\alpha$-stimulating activity into a potent type I IFN inducer.

The results showed that a short (12-mer) K-ODN and the HIVderived cationic peptide $\mathrm{Tat}_{(47-57)}$ condensed to form 200- to 300-nmsized uniform nanorings but not aggregates. In contrast to the typical ODN/cationic peptide aggregates formed with LL-37, the nanorings were significantly more nuclease-resistant and stimulated secretion of large amounts of IFNa from pDCs and IP-10 from monocytes. Flow cytometry and confocal studies confirmed that the nanorings enhanced ODN internalization and localization to transferrin-positive early endosomes, a subcellular distribution pattern consistent with efficient IFNa 


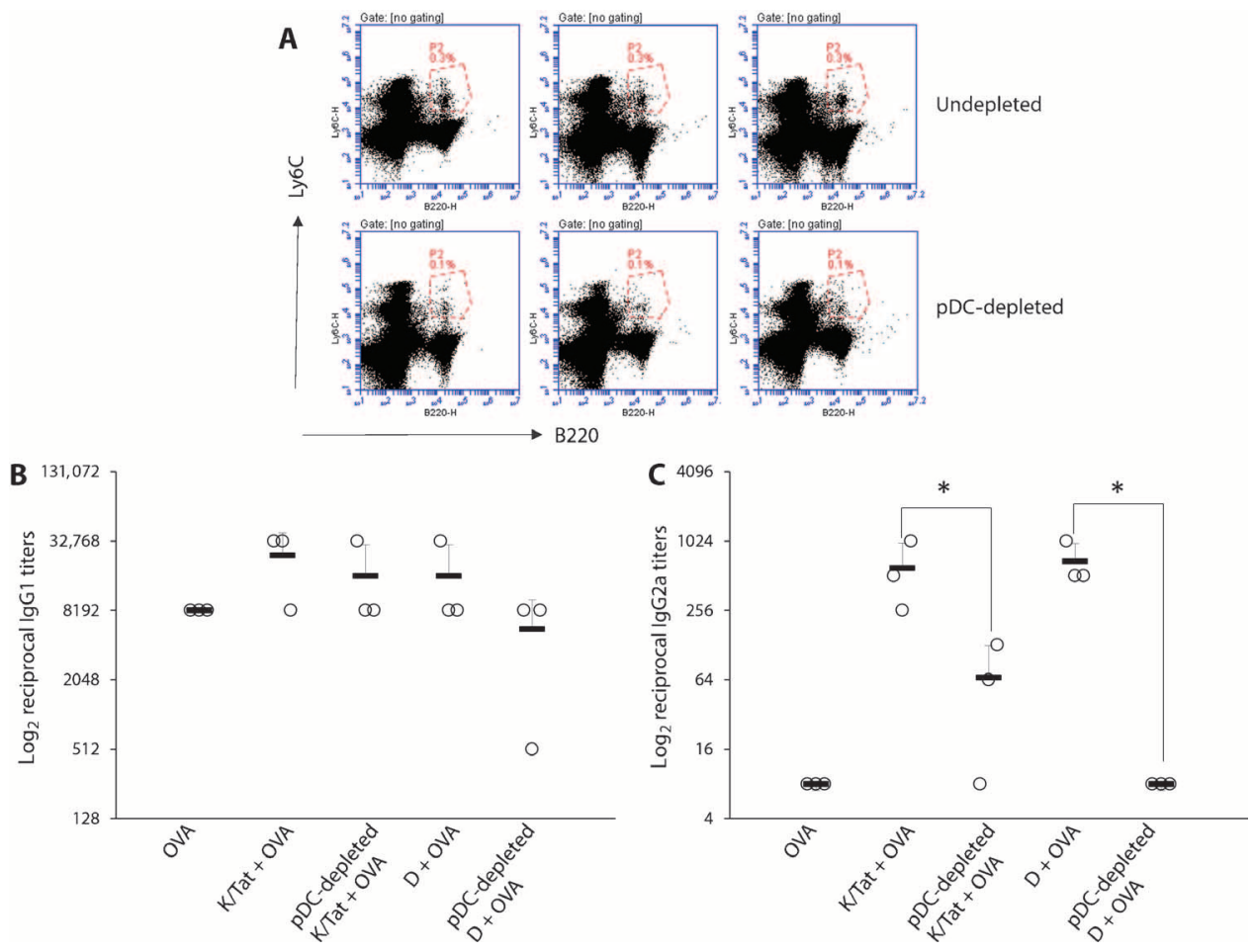

Fig. 7. The vaccine adjuvant activities of $K /$ Tat nanorings and $D-O D N$ are dependent on the presence of pDCs. Mice were treated intraperitoneally with PBS (undepleted groups) or an antibody to mPDCA-1 (500 mg per mouse) and then immunized 24 hours later with $\mathrm{K} / \mathrm{Tat}+$ OVA or D-ODN + OVA (15 $\mu \mathrm{g}$ of ODN and $10 \mu \mathrm{g}$ of OVA per mouse). (A) Depletion of pDCs was confirmed in the peripheral blood on the day of immunization. Dot plots show representative percentages of the Ly6C/B220 double-positive pDCs in pDC-undepleted (upper panels) and pDC-depleted (lower panels) groups. (B and C) OVA-specific $\lg G 1$ (B) and lgG2a (C) $\log _{2}$ reciprocal titers were determined from sera of mice 14 days after priming. Each circle corresponds to the antibody titer of individual mice, and horizontal lines indicate mean antibody titers \pm SD. ${ }^{*} P=0.0404$ based on Mann-Whitney $U$ test $(n=3)$.

production. In vivo, $\mathrm{K} /$ Tat nanorings proved to be potent vaccine adjuvants and induced $\mathrm{T}_{\mathrm{H}} 1$-dominated long-term immune response in mice vaccinated with a $5 \times$ lower dose of a commercially available inactivated viral vaccine against the FMD vaccine. Therapeutic vaccination of C57BL/6 mice bearing OVA-expressing EG.7 thymoma tumors with OVA plus K/Tat nanorings generated superior antitumor immunity when compared to mice treated with OVA plus K-ODN. The in vivo vaccine adjuvant activity of the nanorings was similar to D-ODN and was severely impaired in mice depleted of pDCs, suggesting that pDC activation and their type I IFN production are critical for the vaccine adjuvant activity of the nanorings.

Multimerized CpG ODN are believed to be retained in early endosomes where they cross-link TLR9 and trigger MyD88/IRF7mediated intracellular signaling pathways, leading to IFN $\alpha$ secretion from $\mathrm{pDCs}(27,30,44-47)$. Although K-ODN were shown to trigger production of this cytokine from $\mathrm{pDCs}$ after their conjugation/adsorption onto nanoparticles $(44,48)$ or their multimerization through association with cationic liposomes (45), heat shock protein 90 (49), or long cationic peptides (15-17), such delivery methods suffer from cumbersome nanoparticle production protocols, potential toxicity/immunity associated with the carrier, or unpredictable aggregation/precipitation of the product, deeming them unsuitable for clinical applications. The ease with which the nanorings form and their effectiveness for vaccine dose-sparing applications and stimulating antitumor immunity suggest that as D-ODN surrogates, they may prove to be of value as antiviral or anticancer agents and vaccine adjuvants in the clinic.

Although these results are encouraging for the potential clinical development of a type I IFN inducer, the current study had the following major limitation: All in vivo data were based on murine studies. The cellular distribution of TLR9 in the mouse is much broader than in the human and includes myeloid DCs, pDCs, monocytes, macrophages, and $\mathrm{B}$ cells (as opposed to restricted expression in $\mathrm{pDCs}$ and $\mathrm{B}$ cells in the human) (1-14). Therefore, nonhuman primate studies where the cellular expression of TLR9 is similar to humans would be better suited to predict in vivo adjuvant activity.

\section{MATERIALS AND METHODS}

\section{Study design}

For all experiments, the minimum sample size was determined to detect a difference between group means of two times the observed SD, with a power of 0.8 and a significance level of 0.05 , using the power and sample size calculator (http://www. statisticalsolutions.net/pss_calc.php). On the basis of this, the calculated minimum sample sizes ranged from two to three depending on the experiment. Actual sample size for mouse studies was three to five per group. Throughout the study, hPBMCs were collected from healthy donors (15 different volunteers; ages 20 to 45 years; sex: 8 males and 7 females). All samples were randomized but not blinded.

\section{Reagents}

Endotoxin-free ODN were purchased from Integrated DNA Technologies BVBA. Sequences of ODN used were as follows: K3, ATCGACTCTCGAGCGTTCTC; K3-flip, ATGCACTCTGCAGGCTTCTC; K23, TCGAGCGTTCTC; K23-flip, TGCAGGCTTCTC; D35, GGtgcatcgatgcaggggGG. Bases shown in capital letters are phosphorothioate, and those in lower case are phosphodiester. The cationic peptides LL-37 (LLGDFFRKSKEKIGKEFKRIVQRIKDFLRNLVPRTES), KR-12 (KRIVQRIKDFLR), and HIV Tat ${ }_{(47-57)}$ (YGRKKRRQRRR) and the OVA (257-264) SIINFEKL peptide were synthesized by AnaSpec.

\section{Preparation and characterization of CpG ODN/peptide complexes}

CpG ODN K23 (12-mer), K3 (20-mer), or their GpC (flip) controls were mixed at different molar ratios $(1: 1,1: 2,1: 4,1: 8$, or 1:16) with the antimicrobial cationic peptides LL-37 (37-mer; +6 charge), KR-12 (11-mer, +4 charge), or Tat peptide (11-mer; +8 charge) and were incubated for 
$30 \mathrm{~min}$ at room temperature. Complexes were characterized by dynamic light scattering, $\zeta$ potential measurement, and AFM. For size and $\zeta$ potential measurements, a Malvern Zetasizer Nano ZS was used. The hydrodynamic diameters are reported as the intensity average measured from two independent samples [ $50 \times$ diluted with DNase/RNase (ribonuclease)free distilled water]. Size and morphology of complexes were determined by AFM as follows: $5 \mu \mathrm{l}$ of each sample (in DNase/RNase-free water) was deposited onto a Mica sheet and was allowed to dry at room temperature for $30 \mathrm{~min}$. Noncontact mode images were taken using a PSIA XE-100E model AFM. Tap190AI-G model tips were from NanoSensors. Tips' resonance frequency and force constant were $130 \mathrm{kHz}$ and $20 \mathrm{~N} / \mathrm{m}$, respectively. Scan rate was kept at 0.73 to $0.79 \mathrm{~Hz}$. Images were analyzed with XEI 1.6 software.

Determination of immunostimulatory activity of complexes PBMCs from healthy donors or mouse splenocytes $\left(2 \times 10^{6}\right.$ to $4 \times$ $10^{6} / \mathrm{ml}$ ) were cultured in RPMI 1640 medium containing $5 \%$ fetal calf serum, penicillin $(50 \mathrm{U} / \mathrm{ml})$, streptomycin $(50 \mu \mathrm{g} / \mathrm{ml})$, L-glutamine $(0.3 \mu \mathrm{g} / \mathrm{ml}), 1 \mu \mathrm{M}$ nonessential amino acids, $1 \mu \mathrm{M}$ sodium pyruvate, $10 \mathrm{mM}$ Hepes, and $10^{5} \mathrm{M} 2$-mercaptoethanol. Depending on the identity of the cytokine or chemokine intended for measurement, cells were stimulated with 0.3 to $3 \mu \mathrm{M}$ free ODN or its complexes for a period of 5 to 24 hours. In some experiments, free CpG ODN and CpG ODN/peptide complexes were treated with 1.1 IU of DNase I (from bovine pancreas, Roche) per microgram of ODN for $30 \mathrm{~min}$ before stimulation. IFN $\alpha$-secreting cells were analyzed with Miltenyi Biotec's IFN- $\alpha$ Secretion Assay Detection Kit from PBMCs in accordance with kit instructions. For intracellular cytokine staining, cells were stimulated in the presence of brefeldin A $(10 \mu \mathrm{g} / \mathrm{ml})$ as previously described $(9,27)$. For flow cytometric analysis of cells, the following antibody clones were used: BDCA-2-PE (phycoerythrin) (AC144) from Miltenyi Biotec; CD123-PE-Cy5 (9F5), CD14-FITC (fluorescein isothiocyanate) (M5E2), IP-10-PE (6D4/D6/G2), and TNFo-PE (MAb11) from BD Biosciences; and CD8-PE-Cy5 (53-6.7) and IFN $\gamma$-PE (XMG1.2) from BioLegend. All staining protocols were performed as previously described $(9,27)$. Stained cells were analyzed $(20,000$ to 100,000 events) on a BD Accuri C6 flow cytometer (BD Biosciences) following proper electronic compensation.

\section{Cytokine ELISA}

Ninety-six-well microtiter plates (Millipore) were coated with antibodies specific to human IFN $\alpha$ or IP-10 or mouse IFN $\gamma$. The plates were blocked with PBS-5\% bovine serum albumin (BSA). Supernatants from cultured cells were added, and their cytokine content was quantitated by the addition of biotin-labeled anti-cytokine antibody followed by phosphataseconjugated avidin and phosphatase-specific colorimetric substrate as previously described $(9,27)$. Standard curves were generated using known amounts of recombinant human cytokine. All assays were performed in triplicate, and all washing steps were performed with PBS- $0.05 \%$ Tween 20 .

\section{Analysis of cell surface binding and internalization of ODN}

CAL-1 human plasmacytoid-like DCs $\left(1 \times 10^{6} / \mathrm{ml}\right)$ were incubated with FAM-labeled ODN or its complexes $(0.16$ to $1.5 \mu \mathrm{M})$ for 1 hour at $37^{\circ} \mathrm{C}$ and extensively washed with PBS before analysis on a flow cytometer. To detect internalized ODN, surface-bound ODNFAM signal was quenched using $0.2 \%$ trypan blue (mixed 1:1 with the sample).

\section{Confocal microscopy}

CAL-1 cells $\left(1 \times 10^{6} / \mathrm{ml}\right)$ were incubated with Cy5-labeled ODN or its complexes together with transferrin-Texas Red conjugate $(20 \mu \mathrm{g} / \mathrm{ml})$ (marker for early endosomes) at $37^{\circ} \mathrm{C}$ for 1 hour. All samples were washed, and live cells were immediately analyzed with a confocal microscope under a $63 \times$ objective (Carl Zeiss, LSM).

\section{Immunization studies}

All animal studies were conducted with previous approval of the animal ethics committee of Bilkent University.

The FMD vaccine was prepared and provided by the FMD Institute (Ankara, Turkey). This monovalent vaccine formulation contained FMD vaccine O/TUR/07 inactivated antigen in double oil emulsion with Montanide ISA 206 (SEPPIC). Six- to 8-week-old female BALB/c mice (five per group) were immunized two times (intraperitoneally, days 0 and 15) using $5 \times$ lower dose of the optimal licensed monovalent vaccine ( $0.5 \mu \mathrm{g}$ per mouse) alone or mixed with K-ODN, K/LL-37 (1:8), or $\mathrm{K} / \mathrm{Tat}$ (1:16). CpG ODN dose per mice was adjusted so that each animal received a $5 \times$ lower dose $(2 \mu \mathrm{g})$ of ODN than the optimal adjuvant dose used in mice (10 to $50 \mu \mathrm{g}$ ).

To follow long-term antigen-specific antibody responses, sera were collected 180 days after priming, and FMD-specific antibody titers were determined by ELISA. Briefly, Immulon 1B plates were coated overnight with $50 \mu \mathrm{l}$ of rabbit anti-Ser-O antibody (1:2000 dilution) at $4^{\circ} \mathrm{C}$ and blocked with PBS-5\% BSA. Diluted supernatant (1:20) of the cell lysate of FMD vaccine-infected baby hamster kidney cells was then added to the plates in PBS (50 $\mu \mathrm{l}$ per well) and incubated overnight at $4^{\circ} \mathrm{C}$. Diluted mouse serum $(80 \times)$ was serially diluted twofold, and specific antibodies were detected using goat anti-mouse IgG1 or IgG2a alkaline phosphatase conjugate (1:3000 dilution) followed by PNPP ( $p$-nitrophenyl phosphate, disodium salt) substrate addition. Color development was followed at optical density (OD) $405 \mathrm{~nm}$ with a microplate reader. Antibody titers were expressed as the reciprocal $\log _{2}$ of the last dilution that gave an OD of plus 3 SDs above the average $\mathrm{OD}$ of all dilutions from nonimmunized control mice.

\section{FMD antigen-specific $T$ cell responses generated in immunized mice were assessed using the IFN $\gamma$ production from in vitro FMD antigen $(3 \mu \mathrm{g} / \mathrm{ml})$ restimulated spleen cells by ELISA}

EG.7 tumor cells $\left(2.5 \times 10^{6}\right.$ per mice $)$ were injected subcutaneously into the dorsal flank of C57BL/6 mice (five per group). After the tumors reached a palpable size $\left(\geq 50 \mathrm{~mm}^{3}\right)$, groups of mice received two intraperitoneal injections of $25 \mu \mathrm{g}$ of OVA plus K-ODN or K/Tat $(10 \mu \mathrm{g}$ of ODN, each) 1 week apart. Five days after the first intraperitoneal injection, tumor volumes were measured with a caliper every other day and recorded as length $\times$ width $\times$ height. Animals were sacrificed 8 days after the second intraperitoneal injection, and tumors were excised and weighed. Splenocytes $\left(2.5 \times 10^{6} / \mathrm{ml}\right)$ were stimulated in the absence or presence of SIINFEKL $(2 \mu \mathrm{g} / \mathrm{ml})$ OVA $257-264$ class I (Kb)-restricted peptide epitope for 5 hours together with brefeldin A $(10 \mu \mathrm{g} / \mathrm{ml})$. Cells were stained for cell surface CD8 expression, fixed and permeabilized, and then stained for intracellular IFN $\gamma$ production. Results were analyzed by flow cytometry on CD8-gated cells.

For $\mathrm{pDC}$ depletion experiments, BALB/c mice (three per group) were injected intraperitoneally with $\mathrm{PBS}$ (pDC-undepleted groups) or with antibody to mPDCA-1 (500 mg) (Miltenyi Biotec; clone JF051C2.4.1; pure-functional grade) 24 hours before immunization with 
$10 \mu \mathrm{g}$ of OVA without or with $15 \mu \mathrm{g}$ of K/Tat or $15 \mu \mathrm{g}$ of D-ODN. To confirm pDC depletion 24 hours after antibody injection, $100 \mu \mathrm{l}$ of blood was collected from tail veins into heparinized tubes and red blood cells were lysed using ACK lysis buffer. After Fc blocking with an antibody to CD16/32, peripheral blood cells were stained with FITC-conjugated antibody to Ly6C and Alexa Fluor 647-conjugated antibody to CD45R/ B220 for $30 \mathrm{~min}$ at room temperature and washed with PBS containing $1 \%$ BSA. The percentage of the Ly6C/B220 double-positive pDCs was determined with flow cytometry. Sera were collected 14 days after priming, and OVA-specific antibody titers were determined by ELISA. Briefly, Immulon 1B plates were coated overnight with $50 \mu$ l of OVA protein $(7.5 \mu \mathrm{g} / \mathrm{ml})$ at $4^{\circ} \mathrm{C}$ and blocked with PBS-5\% BSA. Diluted mouse serum $(8 \times)$ was serially diluted fourfold, and specific antibodies were detected using goat anti-mouse IgG1 or IgG2a alkaline phosphatase conjugate (1:3000 dilution) followed by PNPP substrate addition. Color development was followed at OD $405 \mathrm{~nm}$ with a microplate reader. Antibody titers were expressed as the reciprocal $\log _{2}$ of the last dilution that gave an OD of plus 3 SDs above the average OD of all dilutions from nonimmunized control mice.

\section{Statistical analysis}

For groupwise comparisons, stimulation indexes (fold induction) were subjected to the Mann-Whitney $U$ test. Comparison of $\log _{2}$-transformed FMD-specific antibody titers and FMD-specific IFN $\gamma$ production between groups was performed using one-way ANOVA with Tukey's HSD post hoc test $(P<0.05)$. For comparison of antitumor responses elicited in mice immunized with OVA + K-ODN versus OVA + K/Tat nanorings, two-tailed unpaired Student's $t$ test was used. For all comparisons, 95\% confidence intervals were used and $P$ values of $<0.05$ were considered significant. All analyses were done with the SPSS 22.0 statistics software. Statistical tests used to determine significance, sample sizes, and $P$ values are provided in individual figure legends or in supplementary tables.

\section{SUPPLEMENTARY MATERIALS}

www.sciencetranslationalmedicine.org/cgi/content/full/6/235/235ra61/DC1 Method

Fig. S1. Secondary structure predictions of the 20-mer CpG ODN (left) and the 12-mer CpG ODN (right) were generated using the M-fold program.

Fig. S2. Physical properties of K-ODN/cationic peptide complexes prepared using various ODN/peptide ratios.

Fig. S3. IFNo-inducing activity does not correlate with particle size.

Fig. S4. IFN $\alpha$-stimulating activity of various K-ODN/cationic peptide complexes in hPBMCs.

Fig. S5. K-ODN/cationic peptide complexes are not cytotoxic and do not trigger inflammasome activation.

Fig. S6. K-ODN/cationic peptide complexes trigger TNF $\alpha$ production from pDCs.

Table S1. Average particle size, $\mathrm{Pl}$, and $\zeta$ potential measurements of complexes prepared with the 12- and 20-mer K-ODN.

Table S2. Raw data and statistical significance testing for Fig. 2A.

Table S3. Raw data and statistical significance testing for Fig. 3A.

Table S4. Raw data and statistical significance testing for Fig. 3C.

Table S5. Results of Tukey's HSD post hoc test using one-way ANOVA for Fig. 5.

\section{REFERENCES AND NOTES}

1. A. M. Krieg, CpG still rocks! Update on an accidental drug. Nucleic Acid Ther. 22, 77-89 (2012).

2. J. Vollmer, A. M. Krieg, Immunotherapeutic applications of CpG oligodeoxynucleotide TLR9 agonists. Adv. Drug Deliv. Rev. 61, 195-204 (2009).

3. K. J. Ishii, S. Akira, Innate immune recognition of, and regulation by, DNA. Trends Immunol. 27, 525-532 (2006).
4. D. M. Klinman, Immunotherapeutic uses of $\mathrm{CpG}$ oligodeoxynucleotides. Nat. Rev. Immunol. 4, 249-258 (2004).

5. C. Bode, G. Zhao, F. Steinhagen, T. Kinjo, D. M. Klinman, CpG DNA as a vaccine adjuvant. Expert Rev. Vaccines 10, 499-511 (2011).

6. G. Hartmann, A. M. Krieg, Mechanism and function of a newly identified CpG DNA motif in human primary B cells. J. Immunol. 164, 944-953 (2000).

7. D. Verthelyi, K. J. Ishii, M. Gursel, F. Takeshita, D. M. Klinman, Human peripheral blood cells differentially recognize and respond to two distinct CpG motifs. J. Immunol. 166, 2372-2377 (2001).

8. A. Krug, S. Rothenfusser, V. Hornung, B. Jahrsdörfer, S. Blackwell, Z. K. Ballas, E. Endres, A. M. Krieg, G. Hartmann, Identification of CpG oligonucleotide sequences with high induction of IFN- $\alpha / \beta$ in plasmacytoid dendritic cells. Eur. J. Immunol. 31, 2154-2163 (2001).

9. M. Gürsel, D. Verthelyi, I. Gürsel, K. J. Ishii, D. M. Klinman, Differential and competitive activation of human immune cells by distinct classes of CpG oligodeoxynucleotide. J. Leukoc. Biol. 71, 813-820 (2002).

10. M. Kerkmann, L. T. Costa, C. Richter, S. Rothenfusser, J. Battiany, V. Hornung, J. Johnson, S. Englert, T. Ketterer, W. Heckl, S. Thalhammer, S. Endres, G. Hartmann, Spontaneous formation of nucleic acid-based nanoparticles is responsible for high interferon- $\alpha$ induction by CpG-A in plasmacytoid dendritic cells. J. Biol. Chem. 280, 8086-8093 (2005).

11. M. Puig, A. Grajkowski, M. Boczkowska, C. Ausín, S. L. Beaucage, D. Verthelyi, Use of thermolytic protective groups to prevent G-tetrad formation in CpG ODN type D: Structural studies and immunomodulatory activity in primates. Nucleic Acids Res. 34, 6488-6495 (2006).

12. G. Hartmann, J. Battiany, H. Poeck, M. Wagner, M. Kerkmann, N. Lubenow, S. Rothenfusser, S. Endres, Rational design of new CpG oligonucleotides that combine B cell activation with high IFN- $\alpha$ induction in plasmacytoid dendritic cells. Eur. J. Immunol. 33, 1633-1641 (2003).

13. J. D. Marshall, K. Fearon, C. Abbate, S. Subramanian, P. Yee, J. Gregorio, R. L. Coffman, G. Van Nest, Identification of a novel CpG DNA class and motif that optimally stimulate B cell and plasmacytoid dendritic cell functions. J. Leukoc. Biol. 73, 781-792 (2003).

14. U. Samulowitz, M. Weber, R. Weeratna, E. Uhlmann, B. Noll, A. M. Krieg, J. Vollmer, A novel class of immune-stimulatory $\mathrm{CpG}$ oligodeoxynucleotides unifies high potency in type I interferon induction with preferred structural properties. Oligonucleotides 20, 93-101 (2010).

15. R. Lande, J. Gregorio, V. Facchinetti, B. Chatterjee, Y. H. Wang, B. Homey, W. Cao, Y. H. Wang, B. Su, F. O. Nestle, T. Zal, I. Mellman, J. M. Schröder, Y. J. Liu, M. Gilliet, Plasmacytoid dendritic cells sense self-DNA coupled with antimicrobial peptide. Nature 449, 564-569 (2007).

16. P. Hurtado, C. A. Peh, LL-37 promotes rapid sensing of CpG oligodeoxynucleotides by $B$ lymphocytes and plasmacytoid dendritic cells. J. Immunol. 184, 1425-1435 (2010).

17. M. Kerkmann, D. Lochmann, J. Weyermann, A. Marschner, H. Poeck, M. Wagner, J. Battiany, A. Zimmer, S. Endres, G. Hartmann, Immunostimulatory properties of CpG-oligonucleotides are enhanced by the use of protamine nanoparticles. Oligonucleotides 16, 313-322 (2006).

18. M. L. Ainalem, R. A. Campbell, T. Nylander, Interactions between DNA and poly(amido amine) dendrimers on silica surfaces. Langmuir 26, 8625-8635 (2010).

19. M. Nakata, G. Zanchetta, B. Chapman, C. Jones, J. Cross, R. Pindak, T. Bellini, N. Clark, Endto-end stacking and liquid crystal condensation of 6 to 20 base pair DNA duplexes. Science 318, 1276-1279 (2007).

20. M. Rapoport, H. Lorberboum-Galski, TAT-based drug delivery system-New directions in protein delivery for new hopes? Expert Opin. Drug Deliv. 6, 453-463 (2009).

21. M. Zanetti, Cathelicidins, multifunctional peptides of the innate immunity. J. Leukoc. Biol. 75, 39-48 (2004).

22. G. Wang, Structures of human host defense cathelicidin LL-37 and its smallest antimicrobial peptide KR-12 in lipid micelles. J. Biol. Chem. 283, 32637-32643 (2008).

23. C. C. Conwell, I. D. Vilfan, N. V. Hud, Controlling the size of nanoscale toroidal DNA condensates with static curvature and ionic strength. Proc. Natl. Acad. Sci. U.S.A. 100, 9296-9301 (2003)

24. D. Argudo, P. K. Purohit, Competition between supercoils and toroids in single molecule DNA condensation. Biophys. J. 103, 118-128 (2012).

25. T. Sarkar, C. C. Conwell, L. C. Harvey, C. T. Santai, N. V. Hud, Condensation of oligonucleotides assembled into nicked and gapped duplexes: Potential structures for oligonucleotide delivery. Nucleic Acids Res. 33, 143-151 (2005).

26. X. Y. Kong, Y. Ding, R. Yang, Z. L. Wang, Single-crystal nanorings formed by epitaxial self-coiling of polar nanobelts. Science 303, 1348-1351 (2004).

27. M. Gursel, I. Gursel, H. S. Mostowski, D. M. Klinman, CXCL16 influences the nature and specificity of CpG-induced immune activation. J. Immunol. 177, 1575-1580 (2006).

28. S. E. Blackwell, A. M. Krieg, CpG-A-induced monocyte IFN- $\gamma$-inducible protein-10 production is regulated by plasmacytoid dendritic cell-derived IFN- $\alpha$. J. Immunol. 170, 4061-4068 (2003).

29. T. Maeda, K. Murata, T. Fukushima, K. Sugahara, K. Tsuruda, M. Anami, Y. Onimaru, K. Tsukasaki, M. Tomonaga, R. Moriuchi, H. Hasegawa, Y. Yamada, S. Kamihira, A novel plasmacytoid dendritic cell line, CAL-1, established from a patient with blastic natural killer cell lymphoma. Int. J. Hematol. 81, 148-154 (2005).

30. K. Honda, Y. Ohba, H. Yanai, H. Negishi, T. Mizutani, A. Takaoka, C. Taya, T. Taniguchi, Spatiotemporal regulation of MyD88-IRF-7 signalling for robust type-I interferon induction. Nature 434, 1035-1040 (2005). 
31. C. Asselin-Paturel, G. Trinchieri, Production of type I interferons: Plasmacytoid dendritic cells and beyond. J. Exp. Med. 202, 461-465 (2005).

32. S. Hervas-Stubbs, J. I. Riezu-Boj, I. Gonzalez, U. Mancheño, J. Dubrot, A. Azpilicueta, I. Gabari, A. Palazon, A. Aranguren, J. Ruiz, J. Prieto, E. Larrea, I. Melero, Effects of IFN- $\alpha$ as a signal-3 cytokine on human naïve and antigen-experienced CD8 ${ }^{+}$T cells. Eur. J. Immunol. 40, 3389-3402 (2010).

33. J. P. Huber, J. D. Farrar, Regulation of effector and memory T-cell functions by type I interferon. Immunology 132, 466-474 (2011).

34. A. M. Davis, H. J. Ramos, L. S. Davis, J. D. Farrar, Cutting edge: A T-bet-independent role for IFN- $\alpha / \beta$ in regulating IL-2 secretion in human $\mathrm{CD}^{+}$central memory T cells. J. Immunol. 181, 8204-8208 (2008).

35. G. A. Kolumam, S. Thomas, L. J. Thompson, J. Sprent, K. Murali-Krishna, Type I interferons act directly on CD8 T cells to allow clonal expansion and memory formation in response to viral infection. J. Exp. Med. 202, 637-650 (2005).

36. T. R. Doel, Natural and vaccine-induced immunity to foot and mouth disease: The prospects for improved vaccines. Rev. Sci. Tech. 15, 883-911 (1996).

37. M. Rweyemamu, P. Roeder, D. Mackay, K. Sumption, J. Brownlie, Y. Leforban, J. F. Valarcher, N. J. Knowles, V. Saraiva, Epidemiological patterns of foot-and-mouth disease worldwide. Transbound Emerg. Dis. 55, 57-72 (2008).

38. G. J. Weiner, H. M. Liu, J. E. Wooldridge, C. E. Dahle, A. M. Krieg, Immunostimulatory oligodeoxynucleotides containing the $\mathrm{CpG}$ motif are effective as immune adjuvants in tumor antigen immunization. Proc. Natl. Acad. Sci. U.S.A. 94, 10833-10837 (1997).

39. Z. K. Ballas, A. M. Krieg, T. Warren, W. Rasmussen, H. L. Davis, M. Waldschmidt, G. J. Weiner, Divergent therapeutic and immunologic effects of oligodeoxynucleotides with distinct CpG motifs. J. Immunol. 167, 4878-4886 (2001).

40. S. M. Geary, C. D. Lemke, D. M. Lubaroff, A. K. Salem, Tumor immunotherapy using adenovirus vaccines in combination with intratumoral doses of $\mathrm{CpG}$ ODN. Cancer Immunol. Immunother. 60, 1309-1317 (2011).

41. Y. Suzuki, D. Wakita, K. Chamoto, Y. Narita, T. Tsuji, T. Takeshima, H. Gyobu, Y. Kawarada, S. Kondo, S. Akira, H. Katoh, H. Ikeda, T. Nishimura, Liposome-encapsulated CpG oligodeoxynucleotides as a potent adjuvant for inducing type 1 innate immunity. Cancer Res. 64, 8754-8760 (2004).

42. D. Wakita, K. Chamoto, Y. Zhang, Y. Narita, D. Noguchi, H. Ohnishi, T. Iguchi, T. Sakai, H. Ikeda T. Nishimura, An indispensable role of type-1 IFNs for inducing CTL-mediated complete eradication of established tumor tissue by CpG-liposome co-encapsulated with model tumor antigen. Int. Immunol. 3, 425-434 (2006).

43. J. Baines, E. Celis, Immune-mediated tumor regression induced by CpG-containing oligodeoxynucleotides. Clin. Cancer Res. 9, 2693-2700 (2003).

44. S. Chinnathambi, S. Chen, S. Ganesan, N. Hanagata, Binding mode of CpG oligodeoxynucleotides to nanoparticles regulates bifurcated cytokine induction via Toll-like receptor 9. Sci. Rep. 2, 534 (2012).

45. T. Hass, F. Schmitz, A. Heit, H. Wagner, Sequence independent interferon- $\alpha$ induction by multimerized phosphodiester DNA depends on spatial regulation of Toll-like receptor- 9 activation in plasmacytoid dendritic cells. Immunology 126, 290-299 (2008).
46. H. Fujita, T. Kitawaki, T. Sato, T. Maeda, S. Kamihira, A. Takaori-Kondo, N. Kadowaki, The tyrosine kinase inhibitor dasatinib suppresses cytokine production by plasmacytoid dendritic cells by targeting endosomal transport of CpG DNA. Eur. J. Immunol. 43, 93-103 (2013).

47. C. Guiducci, G. Ott, J. H. Chan, E. Damon, C. Calacsan, T. Matray, K. D. Lee, R. L. Coffman, F. J. Barrat Properties regulating the nature of the plasmacytoid dendritic cell response to Toll-like receptor 9 activation. J. Exp. Med. 203, 1999-2008 (2006).

48. K. Zwiorek, C. Bourquin, J. Battiany, G. Winter, S. Endres, G. Hartmann, C. Coester, Delivery by cationic gelatin nanoparticles strongly increases the immunostimulatory effects of $\mathrm{CpG}$ oligonucleotides. Pharm. Res. 25, 551-562 (2008).

49. K. Okuya, Y. Tamura, K. Saito, G. Kutomi, T. Torigoe, K. Hirata, N. Sato, Spatiotemporal regulation of heat shock protein 90-chaperoned self-DNA and CpG-oligodeoxynucleotide for type I IFN induction via targeting to static early endosome. J. Immunol. 184, 7092-7099 (2010).

Acknowledgments: We acknowledge technical assistance from Z. E. Ulger, M. Urel, and A. Dana. M. Alkan and C. Cokcalıskan of The Foot and Mouth Disease Institute are acknowledged for supplying the FMD vaccine. We thank I. C. Ayanoglu for his help with statistical analysis. Funding: Scientific and Technological Research Council of Turkey (TUBITAK grant 111S151 to B.G.). Author contributions: B.G. and F.C.Y. performed the experiments and analyzed the data. G.T. assisted with dynamic light scattering and $z$ potential measurements. B.B. assisted with AFM. E.A., S.Y., and M.O. tested ODN lots and assisted with in vivo experiments. I.G. performed confocal microscopy, designed and supervised in vivo experiments, interpreted the data, and edited the manuscript. M.G. conceived the project, designed and supervised the experiments, interpreted the data, wrote the manuscript, and was the principal investigator of the major supporting grant. Competing interests: M.G. and I.G. are among the co-inventors of patents concerning the activity of CpG ODN, including their use as vaccine adjuvants. The rights to all such patents have been transferred to the U.S. government. The authors declare no competing financial interests. Data and materials availability: Patents: "Methods of altering an immune response induced by $\mathrm{CpG}$ oligodeoxynucleotides" [U.S. Patent and Trademark Office (USPTO) \#8,473,342]; "CpG oligodeoxynucleotides encapsulated in sterically stabilized cationic liposomes as immunotherapeutic agents" (USPTO \#7,666,674); "Method of rapid generation of mature dendritic cells" (PCT patent, publication number: WO/2003/020884); "Oligodeoxynucleotide and its use to induce an immune response" (U.S. Patent: Document Number: 20030060440).

Submitted 29 October 2013

Accepted 27 March 2014

Published 7 May 2014

10.1126/scitransImed.3007909

Citation: B. Gungor, F. C. Yagci, G. Tincer, B. Bayyurt, E. Alpdundar, S. Yildiz, M. Ozcan, I. Gursel, M. Gursel, CpG ODN nanorings induce IFN $\alpha$ from plasmacytoid dendritic cells and demonstrate potent vaccine adjuvant activity. Sci. Transl. Med. 6, 235 ra61 (2014). 


\section{An Adjuvant That Has a Ring to It}

Adjuvants are vaccines' little helpers--they modify the immune response to the vaccine antigen. CpG oligodeoxynucleotides (ODN) are short single-stranded synthetic DNA molecules that activate the immune system. Hence, ODN are considered prime candidates for use as adjuvants. Indeed, they've been shown to be effective for both preventing and treating infectious disease and cancers in animal models and early clinical trials. Yet, there are limitations to widespread use of ODN as an adjuvant, one of which is structurally optimizing the ODN to induce the desired immune response. Now, Gungor et al. use the HIV-derived peptide Tat(47-57) to multimerize K-type ODN, forming a nanoring.

The authors found that these nanorings targeted the ODN to early endosomes and induced a type I interferon response in human plasmacytoid dendritic cells. The ODN nanorings were then tested in animal models. They induced $T_{H} 1$ immune responses in mice vaccinated with inactivated foot and mouth disease virus, and improved antitumor immunity in a mouse cancer model. These data suggest that these nanorings may be valuable as either antiviral or anticancer agents.

A complete electronic version of this article and other services, including high-resolution figures, can be found at: http://stm.sciencemag.org/content/6/235/235ra61.full.html

Supplementary Material can be found in the online version of this article at: http://stm.sciencemag.org/content/suppl/2014/05/05/6.235.235ra61.DC1.html

Related Resources for this article can be found online at: http://stm.sciencemag.org/content/scitransmed/5/216/216rv4.full.html http://stm.sciencemag.org/content/scitransmed/3/85/85ra48.full.html http://stm.sciencemag.org/content/scitransmed/6/263/263ra160.full.html http://www.sciencemag.org/content/sci/348/6236/760.full.html http://www.sciencemag.org/content/sci/348/6236/803.full.html

Information about obtaining reprints of this article or about obtaining permission to reproduce this article in whole or in part can be found at:

http://www.sciencemag.org/about/permissions.dtl 